\title{
MENINGKATKAN MINAT BERUSAHATANI BENIH PADI BERSERTIFIKAT MELALUI PENDEKATAN KEUNTUNGAN FINANSIAL
}

\author{
R. Dianda ${ }^{1 \mathrm{a}}, \mathrm{H}$. Miftah $^{1 \mathrm{a}}$ dan A. Yoesdiarti ${ }^{1}$ \\ ${ }^{1}$ Jurusan Agribisnis, Fakultas Pertanian, Universitas Djuanda Bogor \\ Jl. Tol Ciawi No. 1, Kotak Pos 35 Ciawi, Bogor 16720. \\ ${ }^{a}$ Korespondensi: Himmatul Miftah, Telp: 08568049670 E-mail: hmiftah@yahoo.co.id
}

\begin{abstract}
The introduction of rice seed breeder farms has not been captived by many farmers. It is presume that that rice farming for seed breeders is considered not profitable enough compared to consumption rice farming. This study aims to compare financially the rice paddy seed farming for seeds to rice paddy farming for consumption. The study was held in the Gemah Ripah Farmers Group in Cijalingan Village, Cicantayan Sub District, Sukabumi District, West Java. Respondents selected by census, concisted of 24 paddy rice breeders and 20 consumption of paddy rice farmers. Datas were analyzed quantitatively by comparing income, $\mathrm{R} / \mathrm{C}$ analysis, break-even point (BEP) analysis.

The research shows that in the area of 0.675 ha, the profit of rice seed breeder farming is $92.01 \%$ greater than that of consumption rice farming. $\mathrm{R} / \mathrm{C}$ is $18 \%$ bigger; $\mathrm{BEP}$ of price is $10.8 \%$ cheaper; BEP units are $40 \%$ lower and BEP production costs are $36.2 \%$ cheaper than consumption rice farming.
\end{abstract}

Keywords: Financial Analysis, Rice Seed Breeder Farms, R/C analysis, BEP Value

\begin{abstract}
ABSTRAK
Diperkenalkannnya usahatani penangkar benih padi sawah belum banyak diikuti oleh petani, salah satu penyebabnya diduga usahatani padi penangkar benih secara finansial belum menguntungkan dibanding usahatani padi konsumsi. Penelitian ini bertujuan untuk mengetahui dan menganalisis finansial usahatani benih padi sawah untuk benih dibanding konsumsi, penelitian dilaksanakan di Gabungan Kelompok Tani Gemah Ripah Desa Cijalingan Kecamatan Cicantayan Kabupaten Sukabumi Jawa Barat. Pemilihan responden dilakukan secara sensus, yaitu petani penangkar benih padi sawah sebanyak 24 orang dan 20 orang petani padi sawah konsumsi. Data dianalisis secara kuantitatif dengan membandingkan pendapatan, analisis R/C, analisis titik impas (Break Event Point/BEP).

Pada luasan 0,675 Ha, hasil analisis menunjukkan bahwa secara finansial keuntungan usahatani penangkar benih padi $92,01 \%$ lebih besar dibandingkan usahatani padi konsumsi; $\mathrm{R} / \mathrm{C}$ lebih besar $18 \%$; BEP harga lebih murah 10,8 \%; BEP unit lebih rendah $40 \%$ dan BEP biaya produksi lebih murah 36,2\% dibanding usahatani padi konsumsi.

Kata Kunci : Analisis Finansial, Penangkar Benih Padi Bersertifikat, Pendapatan Usahatani, Rasio R/C, Nilai BEP
\end{abstract}




\section{PENDAHULUAN}

Beras sebagai bahan pangan pokok tingkat konsumsinya di Indonesia semakin meningkat seiring dengan peningkatan jumlah penduduk, sehingga pemenuhannya senantiasa dilakukan peningkatan produksi padi. Salah satu upaya meningkatkan produksi padi melalui penggunaan benih varietas unggul bersertifikat. Pada tahun 2016 Pemerintah Republik Indonesia mengeluarkan Peraturan Menteri Pertanian Nomor : 036/HK.150/C/01/2016 Tentang Pedoman Teknis Penguatan Desa Mandiri Benih yang merupakan bagian dari kebijakan Program Kerja Presiden Republik Indonesia yang tertuang dalam Rencana Pembangunan Jangka Menengah Nasional 2015-2019. Dengan tujuan yaitu untuk memantapkan kegiatan Pengembangan Seribu Desa Mandiri Benih 2015 khususnya untuk menunjang produktivitas padi (Direktorat Jenderal Tanaman Pangan, 2016).

Pemenuhan penggunaan benih padi pada budidaya padi diperlukan produksi benih varitas unggul bersertifikat. Benih bersertifikat adalah ciri utama dalam menilai benih yang berkualitas. Berdasarkan Undang - undang Nomor 12 Tahun 2012 dan Peraturan Menteri Pertanian Nomor 39 Tahun 2006 disebutkan bahwa benih yang beredar di pasaran harus bersertifikat. Ciri benih bersertifikat yaitu sudah memiliki data, asal-usul keturunan yang jelas dan dapat dilihat pada label yang terpasang di luar atau di dalam kemasan benih (Permentan, 2006)

Salah satu lembaga yang memproduksi benih varietas unggul bersertifikat yaitu Gabungan Kelompok Tani Gemah Ripah yang mulai kegiatan menjadi penangkar benih padi bersertifikat sejak 2015. Kenyataan di lapangan bahwa ketersediaan benih padi varietas unggul bersertifikat di Gabungan Kelompok Tani Gemah Ripah pada saat ini belum optimal karena kurangnya minat menjadi petani produsen penangkar benih sehingga produksinya masih belum memenuhi jumlah yang dibutuhkan. Target produksi benih padi sawah varietas unggul bersertifikat siap jual sebanyak 45 ton per musim tanam, sementara yang dapat terpenuhi hanya tercapai 20 ton per musim tanam. Kurangnya minat ini diperkirakan karena petani berasumsi bahwa pendapatan penangkar benih tidak terlalu menguntungkan dibandingkan budidaya padi konsumsi. Tujuan dari penelitian ini adalah untuk menganalisis pendapatan usahatani benih padi sawah varietas unggul bersertifikat dan pendapatan usahatani padi sawah konsumsi di Gabungan Kelompok Tani Gemah Ripah Desa Cijalingan Kecamatan Cicantayan Kabupaten Sukabumi Jawa Barat.

\section{BAHAN DAN METODE}

\section{Lokasi dan Pengumpulan Data}

Penelitian ini dilakukan di Gabungan Kelompok Tani Gemah Ripah Desa Cijalingan Kecamatan Cicantayan Kabupaten Sukabumi Jawa Barat yang merupakan kelompok petani penangkar benih padi sawah varietas unggul bersertifikat di Kecamatan Cicantayan. Penelitian ini dilakukan mulai dari bulan Desember 2017 sampai dengan Maret 2018.

Data yang dikumpulkan dalam penelitian ini meliputi data primer dan data sekunder. Pengumpulan data primer diperoleh melalui wawancara lansung dengan petani penangkar benih padi sawah dan data sekunder yang relevan dengan topik penelitian.

Pengumpulan data dalam penelitian ini menggunakan teknik wawancara dengan kuesioner yang telah ditetapkan dan pemilihan responden dilakukan secara sensus, yaitu petani penangkar benih padi sawah sebanyak 24 orang dan petani padi sawah konsumsi sebanyak 20 orang.

\section{Metode Pengolahan Data dan Analisis Data}

Analisis data dilakukan dengan analisis kuantitatif dan kualitatif untuk mengolah data primer dan sekunder secara 
deskriptif. Analisis kuantitatif digunakan untuk menganalisis finansial dari usahatani yaitu: analisis pendapatan, analisis $\mathrm{R} / \mathrm{C}$, analisis titik impas (Break Event Point/BEP) (Suratiyah, 2009).

Analisis R/C dilakukan untuk melihat perbandingan antara selisih manfaat dengan biaya yang dinilai negatif setelah dikurangi nilainya selama umur usaha diperhitungkan, atau dengan kata lain adalah perbandingan total penerimaan dengan total pengeluaran dari suatu usahatani. Apabila nilai $\mathrm{R} / \mathrm{C}$ usahatani lebih besar dari satu maka usahatani tersebut layak diusahakan (Suratiyah, 2009). Analisis pendapatan usahatani dapat dihitung dengan cara :

$$
\mathrm{I}=\mathrm{TR}-\mathrm{TC}
$$

Keterangan :

$\begin{array}{ll}\mathrm{I} & =\text { Income } \\ \mathrm{TR} & =\text { Total Revenue } \\ \mathrm{TC} & =\text { Total Cost }\end{array}$

Analisis titik impas digunakan untuk mengetahui seberapa besar volume penjualan minimum agar suatu usahatani tidak mendapat kerugian, tetapi juga belum memperoleh keuntungan dengan kata lain keuntungan sama dengan nol atau angka yang menunjukkan ke angka yang menunjukkan penjualan yang mengakibatkan keadaan usahatani tidak mengalami keuntungan atau kerugian (impas) (Suratiyah, 2009). Analisis ini dapat dihitung dengan cara :

$$
\begin{aligned}
& \text { a. } \mathrm{BEP}(\text { Harga })=\frac{\mathrm{TC}}{\mathrm{Y}} \\
& \text { b. } \mathrm{BEP} \text { (Unit) }=\frac{\mathrm{TFC}}{\mathrm{P}-\mathrm{AVC}} \\
& \text { c. BEP Penerimaan } \mathrm{RP}=\frac{\mathrm{TFC}}{1-\frac{\mathrm{AVC}}{\mathrm{P}}}
\end{aligned}
$$

Keterangan :

$$
\begin{aligned}
& \text { TFC }=\text { Total Fixed Cost } \\
& \text { TVC }=\text { Total Variable Cost }
\end{aligned}
$$

$$
\begin{array}{ll}
\mathrm{AVC} & =\text { Average Variable Cost } \\
\mathrm{P} & =\text { Price } \\
\mathrm{BEP} & =\text { Break Event Point }
\end{array}
$$

\section{HASIL DAN PEMBAHASAN}

Tabel 1 menunjukkan bahwa petani penangkar benih padi sawah menjual sebagian hasil produksi yaitu gabah kering panen(GKP) sebagai gabah calon benih dan gabah konsumsi. Dari luas lahan 0,675 hektar gabah yang dijual untuk calon benih sebanyak 625 kilogram . Harga jual gabah calon benih yaitu Rp. 4.500 per kilogram dan harga jual gabah konsumsi yaitu Rp. 4.000 per kilogram. Petani penangkar benih menjual gabah kering panen (GKP) calon benih ke Gabungan Kelompok Tani Gemah Ripah secara langsung sebanyak 625 kilogram dan menjual gabah konsumsi ke tengkulak sebanyak 2.131 kilogram dengan nilai penerimaan total sebesar Rp. 11.337.167. Pada petani padi konsumsi, harga gabah yang ditetapkan yaitu Rp. 4.000 per kilogram. Petani padi sawah konsumsi menjual gabah kering panen (GKP) ke tengkulak secara langsung, dengan jumlah gabah sebanyak 2.971 kilogram dan nilai penerimaan total sebesar Rp. 11.884.000.

Pendapatan bersih petani responden pada usahatani penangkaran benih padi sawah dari luas lahan 0,675 hektar dalam satu kali musim tanam selama empat bulan di Gabungan Kelompok Tani Gemah Ripah yaitu sebesar Rp. 2.643.093. Pendapatan bersih petani responden pada usahatani padi sawah konsumsi dari luas lahan 0,675 hektar dalam satu kali musim tanam selama empat bulan yaitu sebesar Rp. 1.376.508. Nilai R/C pada usahatani penangkaran benih padi sawah dari luas lahan 0,675 hektar di Gabungan Kelompok Tani Gemah Ripah dengan jumlah total gabah calon benih sebanyak 2.756 kilogram yaitu sebesar 1,3 artinya dengan biaya total sebesar Rp. 8.694.074 akan mendapatkan penerimaan 1,3 kali lebih besar dari biaya total yang dikeluarkan. Nilai R/C pada usahatani padi sawah konsumsi dari luas lahan 0,675 hektar 
dengan jumlah total gabah sebanyak 2.971 kilogram yaitu sebesar 1,1 artinya dengan biaya total sebesar Rp. 10.507.492 akan mendapatkan penerimaan 1,1 kali lebih besar dari biaya total yang dikeluarkan. Kedua usahatani ini dinilai layak untuk diusahakan karena memiliki R/C Ratio lebih dari 1.

Analisis titik impas pada usahatani penangkaran benih padi sawah dari luas lahan 0,675 hektar di Gabungan Kelompok Tani Gemah Ripah dalam satu kali musim tanam selama empat bulan, yaitu dihasilkan titik impas/break event point (harga) sebesar Rp. 3.154 per kilogram, titik impas/break event point (unit) diperoleh hasil sebesar 1.337 kilogram dan titik impas/break event point (penerimaan) sebesar Rp. 5.681.713. Analisis titik impas pada usahatani padi sawah konsumsi dari luas lahan 0,675 hektar dalam satu kali musim tanam selama empat bulan, yaitu dihasilkan titik impas/break event point (harga) sebesar Rp. 3.537 per kilogram, titik impas/break event point (unit) diperoleh hasil sebesar 2.228 kilogram dan titik impas/break event point (penerimaan) sebesar Rp. 8.911.983

Tabel 1. Analisis Finansial Usahatani Penangkaran Benih Padi Sawah dan Usahatani Padi Sawah Konsumsi pada Lahan 0,675 Ha selama empat bulan di Gabungan Kelompok Tani Gemah Ripah

\begin{tabular}{|c|c|c|c|c|c|c|}
\hline \multirow[b]{2}{*}{ Uraian } & \multicolumn{3}{|c|}{$\begin{array}{c}\text { Usahatani } \\
\text { Penangkaran Benih Padi Sawah }\end{array}$} & \multicolumn{3}{|c|}{$\begin{array}{c}\text { Usahatani } \\
\text { Padi Sawah Konsumsi } \\
\end{array}$} \\
\hline & $\begin{array}{c}\text { Jumlah } \\
(\mathrm{Kg})\end{array}$ & $\begin{array}{c}\text { Harga } \\
\text { Satuan } \\
(\mathrm{Rp})\end{array}$ & $\begin{array}{c}\text { Jumlah } \\
\text { (Rp) }\end{array}$ & $\begin{array}{c}\text { Jumlah } \\
(\mathrm{Kg})\end{array}$ & $\begin{array}{c}\text { Harga } \\
\text { Satuan } \\
(\mathrm{Rp})\end{array}$ & $\begin{array}{l}\text { Jumlah } \\
\text { (Rp) }\end{array}$ \\
\hline Penerimaan & & & & & & \\
\hline 1. Gabah Benih & 625 & 4.500 & 2.812 .500 & & & \\
\hline 2. Gabah Konsumsi & 2.131 & 4.000 & 8.524 .667 & 2.971 & 4.000 & 11.884 .000 \\
\hline Jumlah & 2.756 & & 11.337 .167 & 2.971 & & 11.884 .000 \\
\hline Biaya & & & & & & \\
\hline 1. Biaya tetap & & & 2.844 .282 & & & 4.127 .642 \\
\hline 2. Biaya variabel & & & 5.849 .792 & & & 6.379 .850 \\
\hline Jumlah & & & 8.694 .074 & & & 10.507 .492 \\
\hline Keuntungan & & & 2.643 .093 & & & 1.376 .508 \\
\hline $\mathrm{R} / \mathrm{C}$ & & & 1,3 & & & 1,1 \\
\hline BEP Harga (Rp) & & & 3.154 & & & 3.537 \\
\hline BEP Unit (Rp/Kg) & & & 1.337 & & & 2.228 \\
\hline BEP Penerimaan (Rp) & & & 5.681 .713 & & & 8.911 .983 \\
\hline
\end{tabular}

Jika diperbandingkan, maka pada luasan 0,675 Ha, keuntungan usahatani penangkar benih padi $92,01 \%$ lebih besar dibandingkan usahatani padi konsumsi. $\mathrm{R} / \mathrm{C}$ ratio penangkar lebih besar $18 \%$ dibandingkan padi konsumsi; BEP harga lebih rendah 10,8 \%; BEP unit lebih rendah $40 \%$ dan BEP biaya produksi lebih murah 36,2 \% dibanding usahatani padi konsumsi. BEP yang lebih rendah menunjukkan bahwa untuk memperoleh keuntungan pada usaha pembenihan padi lebih mudah dibandingkan pada usahatani padi konsumsi.

\section{KESIMPULAN DAN IMPLIKASI KEBIJAKAN}

\section{Kesimpulan}

Usahatani penangkaran benih padi sawah varietas unggul bersertifikat dari luas lahan 0,675 hektar menguntungkan. Keuntungan benih sebesar Rp. 2.643.093 
dengan nilai $\mathrm{R} / \mathrm{C}$ sebesar 1,3 dan titik impas/BEP (harga) sebesar Rp. 3.154, titik impas/BEP (unit) diperoleh Rp.1.337per kilogram, serta titik impas BEP (penerimaan) sebesar Rp. 5.681.713. Usahatani padi sawah konsumsidari luas lahan 0,675 hektar juga dinilai sama menguntungkan, akan tetapi keuntungan yang didapatkan lebih kecil dibanding usahatani benih. Keuntungan padi konsumsi sebesar Rp. 1.376.508 dengan nilai $\mathrm{R} / \mathrm{C}$ 1,1 dan BEP harga sebesar Rp. 3.537, BEP (unit) diperoleh Rp.2.228 per kilogram, serta BEP penerimaan sebesar Rp. 8.911.983.

\section{Implikasi Kebijakan}

1. Usahatani padi sebagai yang dijual sebagai benih dapat dipromosikan kepada petani sehingga meningkatkan minat berproduksi benih padi.

2. Pembinaan dan pendampingan dari penyuluh lebih digiatkan lagi untuk mensosialisasikan bahwa memproduksi benih lebih menguntungkan.

\section{DAFTAR PUSTAKA}

Balai Pengujian Mutu dan Sertifikasi Hasil Pertanian dan Hasil Hutan Provinsi DKI Jakarta. 2004. Prosedur Sertifikasi. Jakarta: BPMSHPHH DKI Jakarta.

Badan Pusat Statistik. 2015. Profil Penduduk Indonesia Hasil Survei Penduduk Antar Sensus (SUPAS).

Badan Pusat Statistik. 2015. Data Penurunan dan Data Kenaikan Produksi Padi Tahun 2014.

Balai Pengawasan Sertifikasi Benih Tanaman Pangan dan Hortikultura Jawa Barat. 2011.Standar Pengujian Laboratorium Sertifikasi Benih. Bandung: BPSBTPH Jawa Barat.

Balai Pengkajian Teknologi Pertanian Jawa Barat. 2007. Teknik Produksi Benih Padi. Bandung: BPTP Jawa Barat
Balai Pengkajian Teknologi Pertanian Jawa Barat. 2014. Deskripsi Varietas Padi Inpari 22-23 dan Inpago 7. Bandung: BPTP Jawa Barat

Departemen Pertanian Republik Indonesia Direktorat Benih. 2007. Pedoman Sertifikasi Benih. Jakarta: Kementan.

Direktorat Jenderal Ketahanan Pangan. 2014. Data Kebutuhan Beras Per Tahun, Kebutuhan Padi Per Tahun, dan Kebutuhan Benih Padi Per Tahun. Jakarta: Dirjen Ketahanan Pangan.

Direktorat Jenderal Tanaman Pangan. 2009. Pedoman Sertifikat Benih

Tanaman Pangan: Peraturan Direktorat Jenderal Tanaman Pangan Nomor 1 Tahun 2009. Bandar Lampung: Dinas Pertanian Tanaman Pangan dan Hortikultura.

Direktorat Jenderal Tanaman Pangan. 2016. Pedoman Teknis Penguatan Desa Mandiri Benih Tahun Anggaran 2016. Jakarta: Direktorat Jenderal Tanaman Pangan.

Dinas Pertanian Tanaman Pangan Povinsi Jawa Barat. 2017. Data Produksi Padi Sawah Menurut Kabupaten/Kota di Kabupaten Sukabumi. Bandung: Distan Jabar. [Diakses 13 Oktober 2017].

Ishaq I. 2009. Petunjuk Teknis Penangkaran Benih Padi. Bandung:Balai Pengkajian Teknologi Pertanian Jawa Barat.

Kartasapoetra AG. 2003. Teknologi Benih: Pengolahan Benih dan Tanaman Praktikum. Jakarta: Rineka Cipta.

Kementerian Pertanian. 2017. Data Produksi, Produktivitas Padi dan Padi Sawah Tahun 2012-2016. Jakarta: Kementan. [Diakses 13 Oktober 2017].

Kementerian Pertanian. 2016. Data Produktivitas Padi Sawah Tahun 2011-2015 di Kabupaten 
Sukabumi. Jakarta: Kementan. [Diakses 13 Oktober 2017].

[Permentan] Peraturan Menteri Pertanian. 2016. Peraturan Menteri Pertanian Nomor 036/HK.150/C/01/2016. Tentang Pedoman Teknis Penguatan Desa Mandiri Benih. Jakarta: Permentan.

[Permentan] Peraturan Menteri Pertanian. 2006. Peraturan Menteri Pertanian Nomor 39/Permentan/OT.140/8/2006.

Penggunaan Benih Sumber. Jakarta: Permentan.

Sensus Ekonomi Nasional. 2016. Perkembangan Konsumsi Rumah
Tangga Per Kapita di Indonesia 2012-2016. Jakarta: Badan Pusat Statistik.

Soekartawi. 2006. Analisis Usahatani. Jakarta: UI Press

Suratiyah K. 2009. Ilmu Usahatani. Depok: Penebar Swadaya.

Sugiono. Priyanti A. Taufiqurahman M. Korlina E. 2012. Introduksi VUB Padi Sawah Irigasi MH di SLPTT Lamongan. Sukamandi: Balai Besar Penelitian Padi.

Sugiyono. 2012. Metode Penelitian Kuantitatif dan Kualitatif. Bandung: Alfabeta.

Yandianto. 2003. Bercocok Tanaman Padi. Bandung: M2S 